\title{
Inulin blend as prebiotic and fat replacer in dairy desserts: Optimization by response surface methodology
}

\author{
P. L. Arcia, ${ }^{\star} \dagger$ E. Costell, ${ }^{*}$ and A. Tárrega*1 \\ *Instituto de Agroquímica y Tecnología de Alimentos, CSIC, Avda. Agustín Escardino, 7. 46980 (Paterna), Valencia, Spain \\ †Laboratorio Tecnológico del Uruguay, Av. Italia 6201, C.P. 11500, Montevideo, Uruguay
}

\begin{abstract}
The purpose of this work was to optimize the formulation of a prebiotic dairy dessert with low fat content $(<0.1 \mathrm{~g} / 100 \mathrm{~g})$ using a mixture of short- and long-chain inulin. Response surface methodology was applied to obtain the experimental design and data analysis. Nineteen formulations of dairy dessert were prepared, varying inulin concentration ( 3 to $9 \mathrm{~g} / 100$ $\mathrm{g})$, sucrose concentration (4 to $16 \mathrm{~g} / 100 \mathrm{~g}$ ), and lemon flavor concentration (25 to $225 \mathrm{mg} / \mathrm{kg}$ ). Sample acceptability evaluated by 100 consumers varied mainly in terms of inulin and sucrose concentrations and, to a lesser extent, of lemon flavor content. An interaction effect among inulin and sucrose concentration was also found. According to the model obtained, the formulation with $5.5 \mathrm{~g} / 100 \mathrm{~g}$ inulin, $10 \mathrm{~g} / 100 \mathrm{~g}$ sucrose and $60 \mathrm{mg} / \mathrm{kg}$ of lemon flavor was selected. Finally, this sample was compared sensorially with the regular fat content $(2.8 \mathrm{~g} / 100 \mathrm{~g})$ sample previously optimized in terms of lemon flavor $(146 \mathrm{mg} / \mathrm{kg})$ and sucrose $(11.4$ $\mathrm{g} / 100 \mathrm{~g})$. No significant difference in acceptability was found between them but the low-fat sample with inulin possessed stronger lemon flavor and greater thickness and creaminess.
\end{abstract}

Key words: optimization, response surface method, dairy dessert, inulin

\section{INTRODUCTION}

Inulin is a mixture of oligo- and polysaccharides, which are composed of fructose units connected by $\beta-(2-1)$ links. Inulin is of interest for the development of healthy products because it simultaneously responds to a variety of consumer demands: it is fiber-enriched, prebiotic, low fat, and low sugar. As a dietary fiber, inulin passes through the digestive tract largely undigested. In the colon, it acts as a prebiotic because it is selectively fermented by the beneficial flora, stimu-

Received September 29, 2010.

Accepted January 14, 2011.

${ }^{1}$ Corresponding author: atarrega@iata.csic.es lates their growth, and reinforces its action against putrefactive microorganisms (Roberfroid et al., 1998). Inulin products containing mainly long-chain molecules are used for fat replacement because in the presence of water they are able to form a particulate gel, thus modifying the product texture and giving rise to a fatlike mouthfeel (Franck, 2002; Tungland and Meyer, 2002). Inulin products containing mainly short-chain molecules enhance flavor and sweetness and are used to partially replace sucrose (Franck, 2002; De Castro et al., 2009; Villegas et al., 2010). Several nutritional studies (Coudray et al., 2003; Biedrzycka and Bielecka, 2004) recommend the use of blends of short- and long-chain inulin to maximize fermentative and prebiotic effects, because they are selectively metabolized in different portions of the large intestine (short-chain inulin in the proximal colon and long-chain inulin in more distal colonic regions). The blend of short- and long-chain inulin at a 50:50 ratio affords some extra advantages in improving prebiotic effectiveness. It enhances calcium absorption and bone mineralization in pubertal adolescents (Abrams et al., 2005) and proves effective in reducing the amount of gas produced while increasing or maintaining its prebiotic effect (Ghoddusi et al., 2007).

Some researchers have analyzed the effect of inulin addition on physical and sensorial characteristics of semisolid dairy products such as yogurt or custard. Long-chain inulin has been used in low-fat yogurts as a fat replacer where it was shown to significantly improve creaminess, mouthfeel, and smoothness (Kip et al., 2006; Modzelewska-Kapituła and Kłębukowska, 2009). In custard desserts, the addition of short-chain inulin enhanced flavor and sweetness although it did not significantly change the texture (González-Tomás et al., 2009). Meanwhile, the addition of long-chain inulin improved creaminess and consistency of low-fat custards (Lobato et al., 2009) and mimicked those of full-fat custard (Tárrega and Costell, 2006). Thus, the inulin blends are expected to modify sensory properties, especially sweetness, flavor, and texture, as reflected by the combined effects of the 2 inulin types. The magnitude of the sensory changes depends on the blend ratio 
Table 1. Experimental design of samples with regular fat content, showing coded and uncoded values of levels

\begin{tabular}{lccccc}
\hline & \multicolumn{2}{c}{ Coded level } & & \multicolumn{2}{c}{ Uncoded level } \\
\cline { 2 - 3 } \cline { 5 - 5 } \cline { 5 - 5 } Formulation & Sucrose & $\begin{array}{c}\text { Lemon } \\
\text { flavor }\end{array}$ & & $\begin{array}{c}\text { Sucrose } \\
(\mathrm{g} / 100 \mathrm{~g})\end{array}$ & $\begin{array}{c}\text { Lemon flavor } \\
(\mathrm{mg} / \mathrm{kg})\end{array}$ \\
\hline 1 & -1 & -1 & & 7 & 75 \\
2 & 1 & -1 & & 13 & 75 \\
3 & -1 & 1 & & 7 & 175 \\
4 & 1 & 1 & & 13 & 125 \\
5 & -2 & 0 & & 16 & 25 \\
6 & 2 & 0 & & 10 & 225 \\
7 & 0 & 2 & & 10 & 125 \\
8 & 0 & 2 & & 10 & \\
$9-16$ & 0 & 0 & &
\end{tabular}

(Cardarelli et al., 2008; Tárrega et al., 2010) and on the total inulin concentration (Bayarri et al., 2010). However, prior knowledge of these sensory changes is not enough to predict acceptance of a given product formulation because it will depend on the extent to which the variation of these sensory characteristics influence consumer response, and also whether it is affected by other ingredients in the formulation.

Response surface methodology (RSM) is a useful tool for optimizing the sensory quality of foods. Following appropriate statistical designs, the experimental data relate the variation in the consumer's response to variations in previously selected factors (Gacula, 1993; Damasio et al., 1999). An optimal formulation maximizes consumer acceptance in that it is the best possible formulation given a fixed set of ingredients (Damasio et al., 1999; Gan et al., 2006; Acosta et al., 2008). Response surface methodology was successfully used to identify the best combination of ingredients in newly developed products with health-promoting characteristics, such as soy-based desserts (Granato et al., 2010a,b), prebiotic beverages with inulin (Villegas et al., 2010), and soy-based beverages (Deshpande et al., 2008). Taking the above into consideration and with the aim of optimizing the formulation of a prebiotic low-fat dessert with a blend of short- and long-chain inulin (50:50), this work studies the effect of this inulin blend concentration, and its possible interaction with sucrose concentration and lemon flavor, on the acceptability of low-fat desserts.

\section{MATERIALS AND METHODS}

\section{Materials}

The following ingredients were used: whole and skim milk powder (Central Lechera Asturiana, GrandaSiero, Spain), modified tapioca starch $(\mathrm{C} *$ CreamTex 75,720, Cerestar, Barcelona, Spain), 2 inulin types: long-chain (Frutafit TEX) and short-chain (Frutafit CLR; both from Sensus, Brenntag Química, Barcelona, Spain), commercial sucrose, lemon flavor 16508A (Lucta SA, Barcelona, Spain), colorant T-PT8-WAS (Chr. Hansen SA, Barcelona, Spain), mineral water (Font Vella, Spain), and preservatives: potassium sorbate and potassium benzoate (Panreac, Quimica SA, Spain). Both whole (3.7 g fat/100 g) and skim milk $(0.11 \mathrm{~g}$ fat $/ 100 \mathrm{~g})$ were prepared $24 \mathrm{~h}$ in advance by dissolving milk powder $(14.4 \mathrm{~g} / 100 \mathrm{~g}$, Central Lechera Asturiana) in mineral water and storing under refrigeration $\left(4 \pm 1^{\circ} \mathrm{C}\right)$.

\section{Experimental Design and Sample Preparation}

For reference sample optimization (regular fat content dessert), a set of samples was prepared with whole milk and varied concentrations of sucrose and lemon flavor. The composition was selected according to a 2-factor central composite design that comprised 16 points: 4 factorial, 4 axial, and 8 central points (Table 1).

For prebiotic low-fat dessert optimization, a second set of samples was prepared with skim milk and varied concentrations of sucrose, lemon flavor, and inulin according to a 3 -factor central composite design with replicates of the central point. It comprised 19 points: 8 factorial, 6 axial, and 5 central points (Table 2). The inulin used corresponded to a mixture of long-chain and short-chain inulin at a ratio of 50:50. Concentration ranges for inulin (from 3 to $9 \mathrm{~g} / 100 \mathrm{~g}$ ), sucrose (from 4 to $16 \mathrm{~g} / 100 \mathrm{~g}$ ), and lemon flavor (from 25 to $225 \mathrm{mg} /$ $\mathrm{kg}$ ) were established based on preliminary assays.

Samples were prepared in batches of 800 g. Starch, sucrose, inulin blend, milk, and colorant were weighed in a flask and mixed under magnetic stirring (paddle stirrer, Heidolph RZR 1, Schwabach, Germany) for 10 min. The flask was placed in a water bath at $97 \pm$ $1^{\circ} \mathrm{C}$ and stirred constantly with a propeller stirrer for $25 \mathrm{~min}$. Then, the sample was cooled in a water bath 
Table 2. Experimental design of low-fat samples with inulin, showing coded and uncoded values of levels

\begin{tabular}{|c|c|c|c|c|c|c|}
\hline \multirow[b]{2}{*}{ Formulation } & \multicolumn{3}{|c|}{ Coded level } & \multicolumn{3}{|c|}{ Uncoded level } \\
\hline & Sucrose & $\begin{array}{l}\text { Lemon } \\
\text { flavor }\end{array}$ & Inulin & $\begin{array}{l}\text { Sucrose } \\
(\mathrm{g} / 100 \mathrm{~g})\end{array}$ & $\begin{array}{l}\text { Lemon flavor } \\
(\mathrm{mg} / \mathrm{kg})\end{array}$ & $\underset{(\mathrm{g} / 100 \mathrm{~g})}{\text { Inulin }}$ \\
\hline 1 & -1 & -1 & -1 & 7 & 75 & 4.5 \\
\hline 2 & 1 & -1 & -1 & 13 & 75 & 4.5 \\
\hline 3 & -1 & 1 & -1 & 7 & 175 & 4.5 \\
\hline 4 & 1 & 1 & -1 & 13 & 175 & 4.5 \\
\hline 5 & -1 & -1 & 1 & 7 & 75 & 7.5 \\
\hline 6 & 1 & -1 & 1 & 13 & 75 & 7.5 \\
\hline 7 & -1 & 1 & 1 & 7 & 175 & 7.5 \\
\hline 8 & 1 & 1 & 1 & 13 & 175 & 7.5 \\
\hline 9 & 0 & 0 & 0 & 10 & 125 & 6 \\
\hline 10 & -2 & 0 & 0 & 4 & 125 & 6 \\
\hline 11 & 2 & 0 & 0 & 16 & 125 & 6 \\
\hline 12 & 0 & -2 & 0 & 10 & 25 & 6 \\
\hline 13 & 0 & 2 & 0 & 10 & 225 & 6 \\
\hline 14 & 0 & 0 & -2 & 10 & 125 & 3 \\
\hline 15 & 0 & 0 & 2 & 10 & 125 & 9 \\
\hline $16-19$ & 0 & 0 & 0 & 10 & 125 & 6 \\
\hline
\end{tabular}

at $20^{\circ} \mathrm{C}$ with stirring for $10 \mathrm{~min}$. Finally, the lemon flavor, preservatives, and the amount of water that had evaporated in the process were added. For samples with inulin, a portion of long-chain inulin $(0.2 \mathrm{~g} / 100 \mathrm{~g}$ of the total weight of sample) was added during sample cooling (seeding). Preliminary studies have shown that when added in this way, inulin acts as a nucleus of crystallization, favoring the formation of more uniform size inulin crystals (Arcia et al., 2010; Glibowski and Pikus, 2011). Finally, the samples were transferred to a closed flask and stored under refrigeration $\left(4 \pm 1^{\circ} \mathrm{C}\right)$.

Sensory evaluation of samples was performed after $48 \mathrm{~h}$ in the case of samples made with whole milk and after $96 \mathrm{~h}$ for samples with skim milk and inulin (time to stabilize the samples according a previous work; Arcia et al., 2010)

\section{Sensory Evaluation}

Sensory evaluation was carried out in a standardized test room (ISO 8589; ISO, 2007) in a morning session. Samples $(40 \mathrm{~mL})$ were served at $10 \pm 1^{\circ} \mathrm{C}$ in white plastic cups coded with 3 -digit random numbers. Each consumer evaluated 4 or 5 samples per session, with samples presented monadically. Mineral water and bread were provided to consumers to rinse their mouths between samples and a 30-s pause was imposed before they were allowed to test the next sample. In each session, sample presentation order was equilibrated among consumers following a Williams design (MacFie et al., 1989).

Acceptability of each sample was evaluated by consumers using a 9 -point hedonic scale $(1=$ dislike extremely, $9=$ like extremely). A total of 124 subjects participated in the study. They were usual consumers (at least once a week) of semisolid dairy desserts. In the case of reference sample optimization, each whole milk sample (Table 1) was evaluated at least by 60 consumers (from 60 to 62 ). For optimization of the prebiotic low-fat dessert (Table 2), each sample was evaluated by at least 84 consumers (from 84 to 89 ).

Finally, 2 wk later, the low-fat dessert and the reference full-fat dessert were produced with their respective optimized formulations and compared. A total of 60 consumers evaluated sample preference and differences in the intensity of samples by paired comparison tests in one session (ISO 5495; ISO, 2005). The 2 samples were presented simultaneously to consumers and they were asked to select the most preferred sample and then the sample with more intense lemon flavor, sweetness, and consistency.

Data were processed by using Compusense 5, release 4.6, software (Compusense Inc., Guelph, Ontario, Canada).

\section{Data Analysis}

One-way ANOVA was performed on acceptability data to study the formulation effect. Homogeneity of variances was analyzed using the Bartlett test. Differences between samples were determined by Fisher test $(\alpha \leq 0.05)$; XLSTAT-Pro Version 2007 (Addinsoft, Paris, France) was used.

In the optimization study, the results were analyzed using RSM (Gacula, 1993). Overall acceptability and composition data were submitted to a multivariate regression analysis and fitted to a second-order model equation provided in the design: 
Table 3. Acceptability of regular fat dairy desserts with different sucrose and lemon flavor concentrations ${ }^{1}$

\begin{tabular}{lc}
\hline Sample & Acceptability \\
\hline 1 & $6.48^{\mathrm{bcd}}$ \\
2 & $6.97^{\mathrm{ab}}$ \\
3 & $6.41^{\mathrm{cd}}$ \\
4 & $6.87^{\mathrm{bc}}$ \\
5 & $4.35^{\mathrm{e}}$ \\
6 & $6.23^{\mathrm{d}}$ \\
7 & $6.10^{\mathrm{d}}$ \\
8 & $6.82^{\mathrm{abc}}$ \\
9 & $7.19^{\mathrm{a}}$ \\
10 & $7.13^{\mathrm{a}}$ \\
11 & $6.92^{\mathrm{abc}}$ \\
12 & $6.98^{\mathrm{ab}}$ \\
13 & $7.05^{\mathrm{ab}}$ \\
14 & $6.97^{\mathrm{ab}}$ \\
15 & $6.82^{\mathrm{abc}}$ \\
$P_{\text {ANOVA }}$ (sample) & $6.97^{\mathrm{ab}}$ \\
$P_{\text {Bartlett Test }}$ (sample) & $<0.001$ \\
\hline
\end{tabular}

${ }^{\mathrm{a} e}$ Fisher's significant differences: acceptability values not sharing letters are significantly different.

${ }^{1}$ Identification of samples as in Table 1.

$$
\begin{aligned}
\mathrm{Y} & =\mathrm{B}_{0}+\mathrm{B}_{1} \mathrm{X}_{1}+\mathrm{B}_{2} \mathrm{X}_{2}+\mathrm{B}_{3} \mathrm{X}_{3}+\mathrm{B}_{11} \mathrm{X}_{1}{ }^{2}+\mathrm{B}_{22} \mathrm{X}_{2}{ }^{2} \\
& +\mathrm{B}_{33} \mathrm{X}_{3}{ }^{2}+\mathrm{B}_{12} \mathrm{X}_{12}+\mathrm{B}_{13} \mathrm{X}_{13}+\mathrm{B}_{23} \mathrm{X}_{23}+\text { Error, }[1]
\end{aligned}
$$

where $\mathrm{Y}$ is the acceptability, $\mathrm{B}_{0}$ is the intercept (constant), $\mathrm{B}_{1}, \mathrm{~B}_{2}, \mathrm{~B}_{3}$ the linear, $\mathrm{B}_{11}, \mathrm{~B}_{22}, \mathrm{~B}_{33}$ the quadratic, and $\mathrm{B}_{12}, \mathrm{~B}_{13}, \mathrm{~B}_{23}$ the interaction effects; $\mathrm{X}_{1}, \mathrm{X}_{2}$, and $\mathrm{X}_{3}$ are the independent variables: concentrations of sucrose (S), lemon flavor (L), and inulin (I) respectively. The software SPSS for Windows 13.0 (SPSS Inc., Chicago, IL) was used.

The significance of differences in sensory properties in the paired comparisons test were established for $\alpha$ $=0.05$ using the Compusense 5, release 5.0, software (Compusense Inc.).

\section{RESULTS AND DISCUSSION}

\section{Acceptability of Desserts with Regular Fat Content: Reference Sample Optimization}

Before optimizing the formulation of the prebiotic low-fat dairy dessert, the most suitable sucrose and lemon flavor concentrations for a dairy dessert with regular fat content $(2.8 \mathrm{~g} / 100 \mathrm{~g}$ of fat) were determined in order to use it as the reference sample. To do so, we evaluated the acceptability of samples with whole milk and different sucrose and lemon flavor levels, selected according to the RSM design (Table 3). Analysis of variance showed that the degree of liking differed significantly among these samples $(F=12.23$, $P<0.001$ ) with scores ranging from 4.4 to 7 . To relate
Table 4. Estimated regression coefficients of the fitted equations obtained for the acceptability of regular fat samples depending on sugar (1) and lemon flavor (2) concentration

\begin{tabular}{lrrrrr}
\hline & \multicolumn{2}{c}{ ANOVA } & & \multicolumn{2}{c}{ Coefficients } \\
\cline { 2 - 3 } \cline { 5 - 6 } & & & & $\begin{array}{c}\text { Estimated } \\
\text { value }\end{array}$ & $\mathrm{SE}$ \\
\hline Item & $F$-value & $P$-value & & 0.088 & 0.638 \\
\hline $\mathrm{B}_{0}$ & & & & & \\
Linear & & & & & \\
$\mathrm{B}_{1}$ & 104.78 & $<0.001$ & & 1.056 & 0.103 \\
$\mathrm{~B}_{2}$ & 9.39 & 0.011 & & 0.014 & 0.005 \\
Quadratic & & & & & \\
$\mathrm{B}_{11}$ & 84.50 & $<0.001$ & & -0.046 & 0.005 \\
$\mathrm{~B}_{22}$ & 7.50 & 0.019 & & $-5 \times 10^{-5}$ & $2 \times 10^{-5}$ \\
\hline & & & & &
\end{tabular}

the differences in acceptability with sample composition, data were fitted to a second-order model. In the selected model, only the statistically significant terms were retained and their corresponding coefficients are shown in Table 4. Thus, the equation that represents the relationship between acceptability and concentrations of sucrose $(\mathrm{S}, \mathrm{g} / 100 \mathrm{~g})$ and lemon flavor $(\mathrm{L}, \mathrm{mg} /$ $\mathrm{kg}$ ) is as follows:

$$
\begin{gathered}
\text { Acceptability }=0.088+0.014 \mathrm{~L}+1.056 \mathrm{~S}-0.046 \mathrm{~S}^{2} \\
-4.96 \times 10^{-5} \mathrm{~L}^{2}\left(\text { adjusted } \mathrm{R}^{2}=0.889\right) .
\end{gathered}
$$

The model was significant $(P=0.002)$ and explained $96.1 \%$ of all variance in data. The lack of fit was significant $(P=0.042)$, indicating that variability not explained by model was attributed mostly to the lack of fit of some data than to the pure error. On observing predicted data, the acceptability of sample 1 was shown to be lower (6.02) than the experimental value (6.47). The model does not have enough flexibility to fit acceptability values for samples with low flavor and sucrose levels, for which it would be expected to obtain higher acceptability values than those predicted by the model.

Both lemon flavor and sucrose concentrations significantly affected product acceptability, with a positive coefficient for the linear term and a negative coefficient for the quadratic term. As can be seen in the surface generated by the model (Figure 1), acceptability showed an inverted-U shape relationship with the concentration of both lemon flavor and sucrose. As the concentration increased acceptability increased until reaching a certain concentration, at which point it leveled off (maximum is increased) and decreased downward to low acceptability values. The contour plot created by the predictive model (Figure 2) indicated that highest acceptability would be obtained for desserts produced with sucrose content in the range of 10.2 to12.5 g/100 
Table 5. Acceptability of low-fat dairy desserts with different inulin, sucrose, and lemon flavor concentrations

\begin{tabular}{lc}
\hline Sample $^{1}$ & Acceptability \\
\hline 1 & $6.29^{\mathrm{abcd}}$ \\
2 & $6.47^{\mathrm{abc}}$ \\
3 & $5.90^{\mathrm{de}}$ \\
4 & $6.24^{\mathrm{abcd}}$ \\
5 & $6.51^{\mathrm{abc}}$ \\
6 & $6.10^{\mathrm{bcde}}$ \\
7 & $6.23^{\mathrm{abcd}}$ \\
8 & $6.05^{\mathrm{cde}}$ \\
9 & $6.56^{\mathrm{ab}}$ \\
10 & $5.03^{\mathrm{g}}$ \\
1 & $5.68^{\mathrm{ef}}$ \\
12 & $6.56^{\mathrm{ab}}$ \\
14 & $6.18^{\mathrm{abcd}}$ \\
15 & $6.33^{\mathrm{abcd}}$ \\
16 & $6.23^{\mathrm{abcd}}$ \\
17 & $6.65^{\mathrm{a}}$ \\
18 & $6.62^{\mathrm{a}}$ \\
$P_{\text {ANOVA }}$ (sample) & $6.49^{\mathrm{abc}}$ \\
$P_{\text {Bartlett Test }}$ (sample) & $6.61^{\mathrm{a}}$ \\
\hline
\end{tabular}

${ }^{a-g}$ Fisher's significant differences: acceptability values not sharing letters are significantly different.

${ }^{1}$ Identification of samples as in Table 2.

$\mathrm{g}$ and with lemon flavor content in the range of 112 to180 mg/kg. For both sucrose and lemon flavor, the concentration for maximum acceptability was the value at which the equation first derivative equaled zero. According to the results, the formulation with a concentration of $11.5 \mathrm{~g} / 100 \mathrm{~g}$ sucrose and $145 \mathrm{mg} / \mathrm{kg}$ of lemon

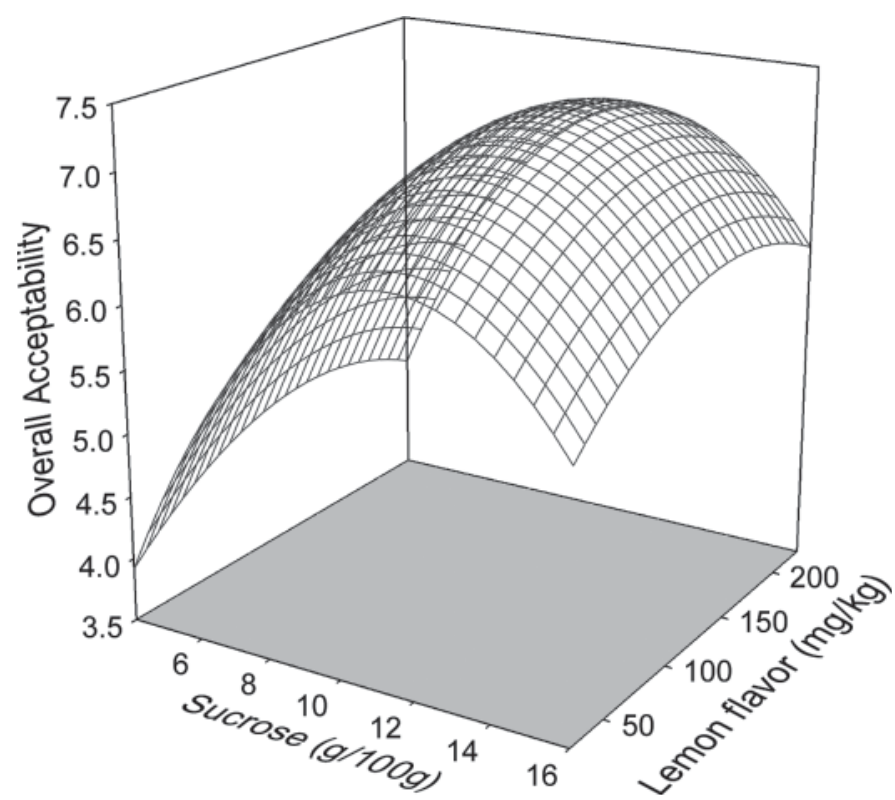

Figure 1. Response surface for the effects of sucrose concentration and lemon flavor concentration on acceptability of regular fat content dairy desserts. flavor was selected as the reference sample with regular fat content.

\section{Acceptability of Low-Fat Desserts with Inulin: Formulation Optimization}

Acceptability of low-fat samples with different concentrations of inulin, sucrose, and lemon flavor was evaluated by consumers. Significant differences in the mean score were observed among samples $(F=6.2 ; P$ $<0.001$ ) with values ranging from 5 to 6.7 (Table 5 ). To explain and model the variation in acceptability in terms of composition variables, data were fitted to a second-order equation for the 3 variables. The significant terms and values of the coefficients of the model that best fit are indicated in Table 6 . For both sucrose and inulin, the linear and quadratic terms were found to be significant. The coefficients for the linear terms were positive and for the quadratic were negative. The term associated with the interaction between the effects of both ingredients was significant and presented a coefficient with negative sign. In the case of lemon flavor, only the quadratic term was significant, with a negative coefficient. Thus, the equation that represents the relationship between overall acceptability and concentrations of inulin (I, g/100 g), sucrose (S, g/100 g) and lemon flavor $(\mathrm{L}, \mathrm{mg} / \mathrm{kg})$ is as follows:

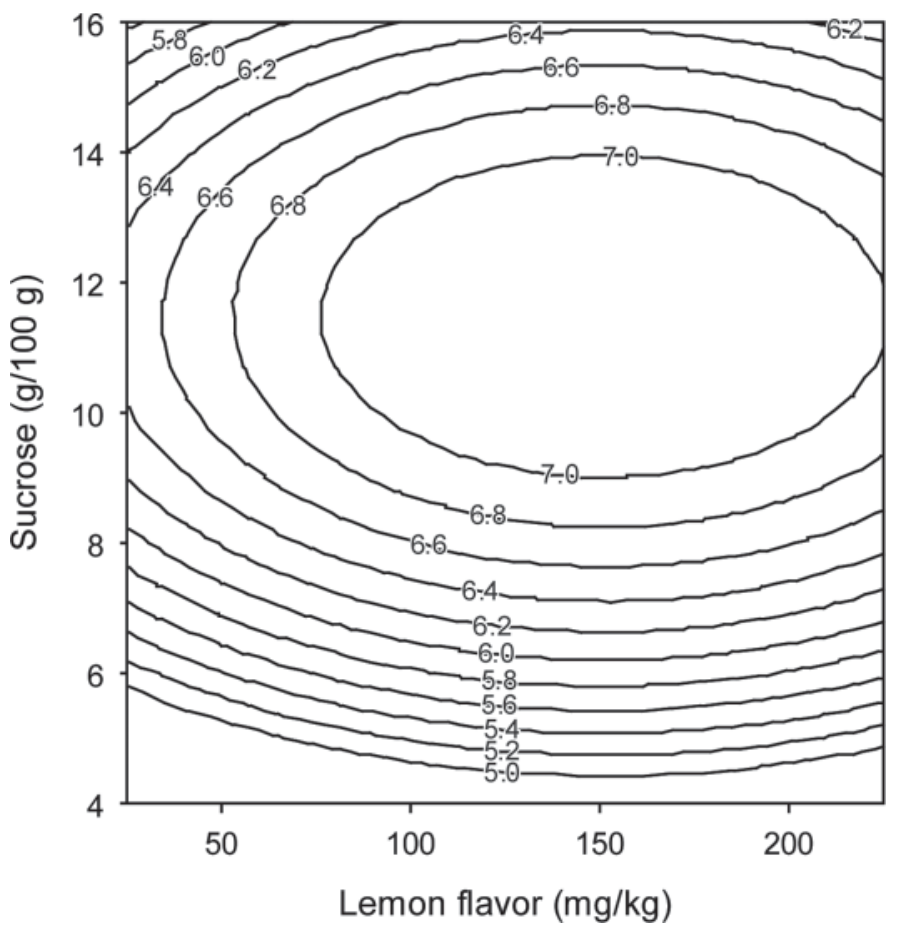

Figure 2. Contour plot of the acceptability of regular fat content dairy dessert as related to sucrose and lemon flavor concentration. 


$$
\begin{gathered}
\text { Acceptability }=0.391+0.869 \mathrm{~S}+0.630 \mathrm{I}-9.06 \\
\times 10^{-6} \mathrm{~L}^{2}-0.033 \mathrm{~S}^{2}-0.028 \mathrm{I}^{2}-0.031 \mathrm{SI} \\
\text { (adjusted } \left.\mathrm{R}^{2}=0.886\right) .
\end{gathered}
$$

The obtained model was significant $(P<0.001)$, it did not present lack of fit $(P=0.055)$, and it could explain $96.1 \%$ of all variance in data. According to the model, overall acceptability of low-fat dessert was mainly affected by inulin and sucrose concentrations. The effects of these 2 variables on acceptability can be observed in Figure 3. As observed for regular fat content desserts, acceptability had an inverted-U shape relationship with sucrose concentration. In this case, because of the inulin-sucrose interaction effect, a maximum was reached at different sucrose concentration values depending on the inulin concentration. The interaction effect was even more evident in the effect of inulin concentration, which changed depending on sucrose concentration. For low sucrose levels, the increase in inulin concentration led to an increase in acceptability, whereas for high sucrose levels, acceptability decreased. The contribution of short-chain inulin molecules to sweetness intensity (Franck, 2002) seems to underlie this interaction. For low sucrose samples, the addition of inulin can compensate the lack of sweetness, thus increasing its acceptability, whereas using high levels of both ingredients led to a decrease in acceptability because of excessive sweetness. The variation in lemon flavor concentration, within the ranges employed in this study, barely affected acceptability, as indicated by the low coefficient value for this component.

The concentration ranges of each ingredient for maximum acceptability were determined using contour plots of the obtained model. It was decided to determine the concentration range for lemon flavor first because it was independent on the other ingredients (no significant interactions). According to Figure 4, maximum acceptability values are obtained for lemon flavor concentrations between 25 and $95 \mathrm{mg} / \mathrm{kg}$.

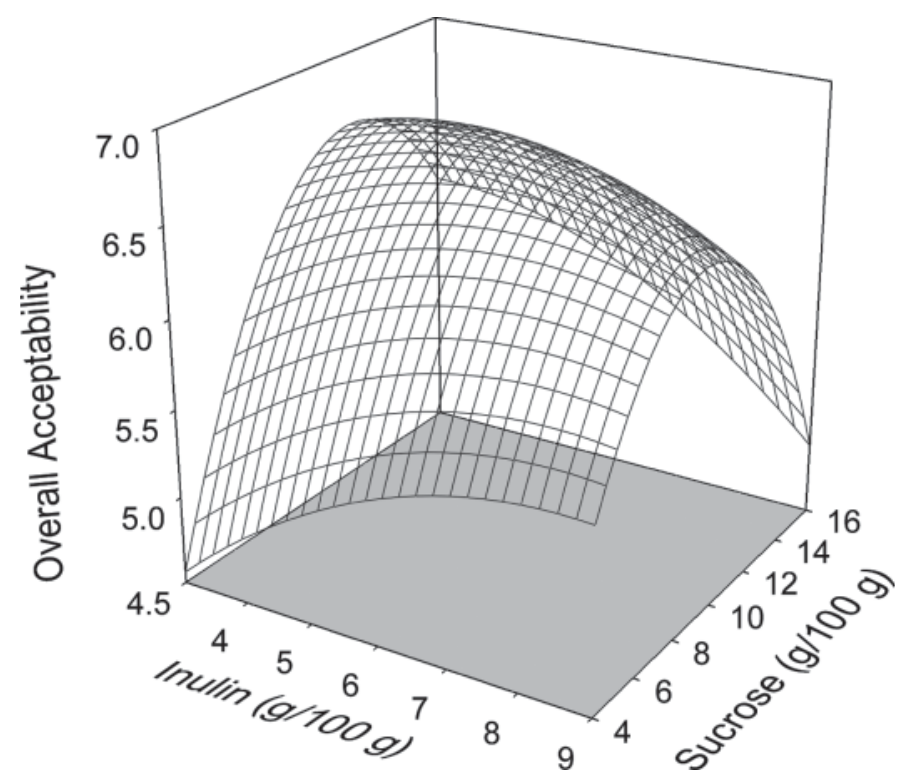

Figure 3. Response surface for the effects of inulin concentration and sucrose concentration on acceptability of low-fat dairy dessert (lemon flavor concentration $=125 \mathrm{mg} / \mathrm{kg}$ ).

At this point, it is interesting to compare Figure 4 with Figure 2, which shows the contour of maximum acceptability for regular fat content desserts at somewhat higher levels of lemon flavor (between 112 and 180 $\mathrm{mg} / \mathrm{kg}$ ). These higher values of lemon flavor concentration in the formulation of regular fat desserts show the effect of fat as a suppressor of aroma release and flavor perception (Weel et al., 2002; González-Tomás et al., 2007; Tárrega et al., 2008).

The optimum ranges for inulin and sucrose were studied in the contour graph for a lemon flavor concentration of $75 \mathrm{mg} / \mathrm{kg}$ (Figure 5). According to this graph, the range of sucrose for which acceptability is highest is between 9 and $12 \mathrm{~g} / 100 \mathrm{~g}$ and for inulin between 4 and $6.5 \mathrm{~g} / 100 \mathrm{~g}$. A representative formulation with maximum acceptability was selected by fixing lemon

\begin{tabular}{|c|c|c|c|c|}
\hline \multirow[b]{2}{*}{ Item } & \multicolumn{2}{|c|}{ ANOVA } & \multicolumn{2}{|c|}{ Coefficients } \\
\hline & $F$-value & $P$-value & $\begin{array}{l}\text { Estimated } \\
\text { value }\end{array}$ & $\mathrm{SE}$ \\
\hline $\mathrm{B}_{0}$ & & & 0.350 & 0.829 \\
\hline \multicolumn{5}{|c|}{ Linear } \\
\hline $\mathrm{B}_{1}$ & 102.66 & $<0.001$ & 0.866 & 0.086 \\
\hline $\mathrm{B}_{3}$ & 13.74 & 0.003 & 0.649 & 0.175 \\
\hline \multicolumn{5}{|c|}{ Quadratic } \\
\hline $\mathrm{B}_{11}$ & 132.62 & $<0.001$ & -0.033 & 0.003 \\
\hline $\mathrm{B}_{22}$ & 11.46 & 0.0054 & $-9 \times 10^{-6}$ & $3 \times 10^{-6}$ \\
\hline $\mathrm{B}_{33}$ & 6.99 & 0.0214 & -0.031 & 0.012 \\
\hline \multicolumn{5}{|c|}{ Interaction } \\
\hline $\mathrm{B}_{13}$ & 7.79 & 0.016 & -0.029 & 0.010 \\
\hline
\end{tabular}

Table 6. Estimated regression coefficients of the fitted equations obtained for the acceptability of the prebiotic low-fat dairy dessert depending on sugar (1), lemon flavor (2), and inulin (3) concentration 


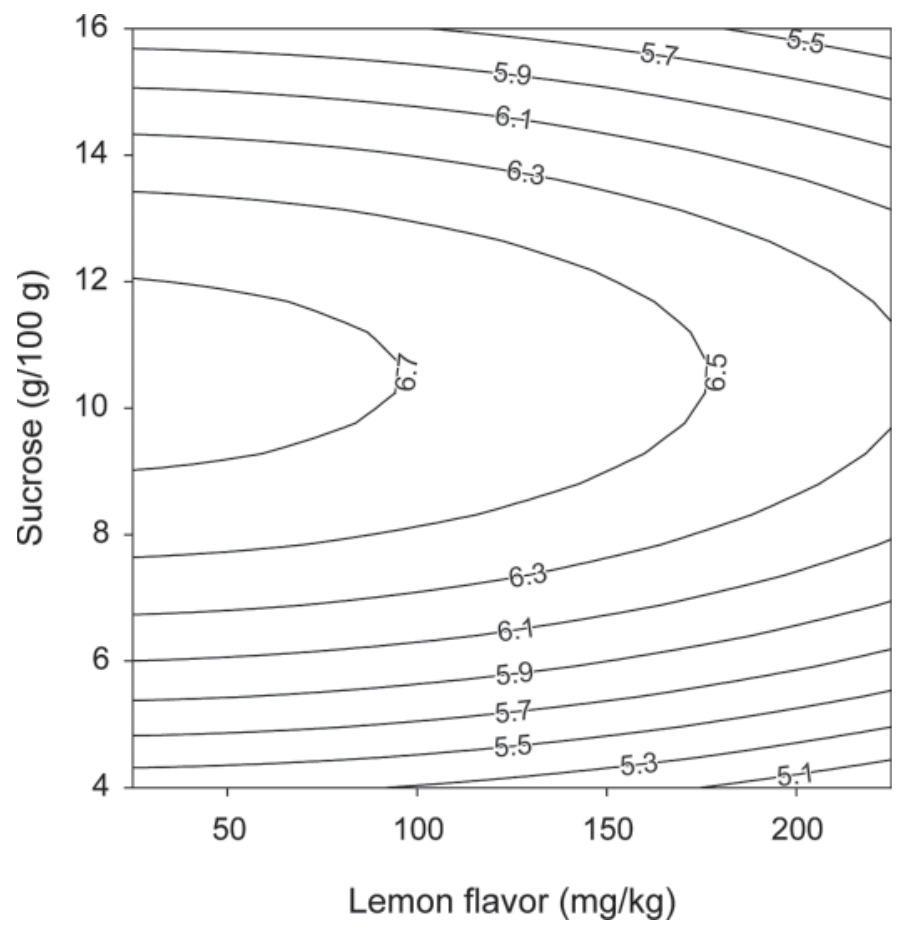

Figure 4. Contour plot of the acceptability of prebiotic low-fat dairy dessert as related to lemon flavor and sucrose concentration (inulin concentration $=6 \mathrm{~g} / 100 \mathrm{~g}$ ).

flavor content at the midpoint of the optimum range and calculating both sucrose and inulin concentration as the value at which the equation first derivative equals zero. The resulting formulation was composed of $10 \mathrm{~g}$ of sucrose $/ 100 \mathrm{~g}, 60 \mathrm{mg}$ of lemon flavor $/ \mathrm{kg}$, and $5.5 \mathrm{~g}$ of inulin/100 g.

The practical use of contour plots is of interest, serving as a database of the acceptability value corresponding to several formulation options. Thus, changes in formulation can be proposed that maintain a balance between acceptability levels and either economic or nutritional benefits. As can be seen, the inulin blend (50:50) can be added at a wide concentration range (from 3 to $7.5 \mathrm{~g} / 100 \mathrm{~g}$ ) and give rise to dairy desserts with high levels of acceptability $(>6.6)$ provided the formulation sugar content is taken into account. For example, for desserts with $3.5 \mathrm{~g}$ of inulin/100 g, sucrose content should be in the range of 10.5 and $13.0 \mathrm{~g} / 100$ $\mathrm{g}$, whereas for samples with higher inulin content $(7.0$ $\mathrm{g} / 100 \mathrm{~g})$, the sucrose concentration range moves to lower values $(8.5-11.5 \mathrm{~g} / 100 \mathrm{~g})$.

\section{Comparison Between the Prebiotic Low-Fat Dairy Dessert and the Regular Fat Content Dessert}

A low-fat dessert was produced with the selected levels of inulin, sucrose, and lemon flavor and compared with the reference dessert with regular fat content. Dif-

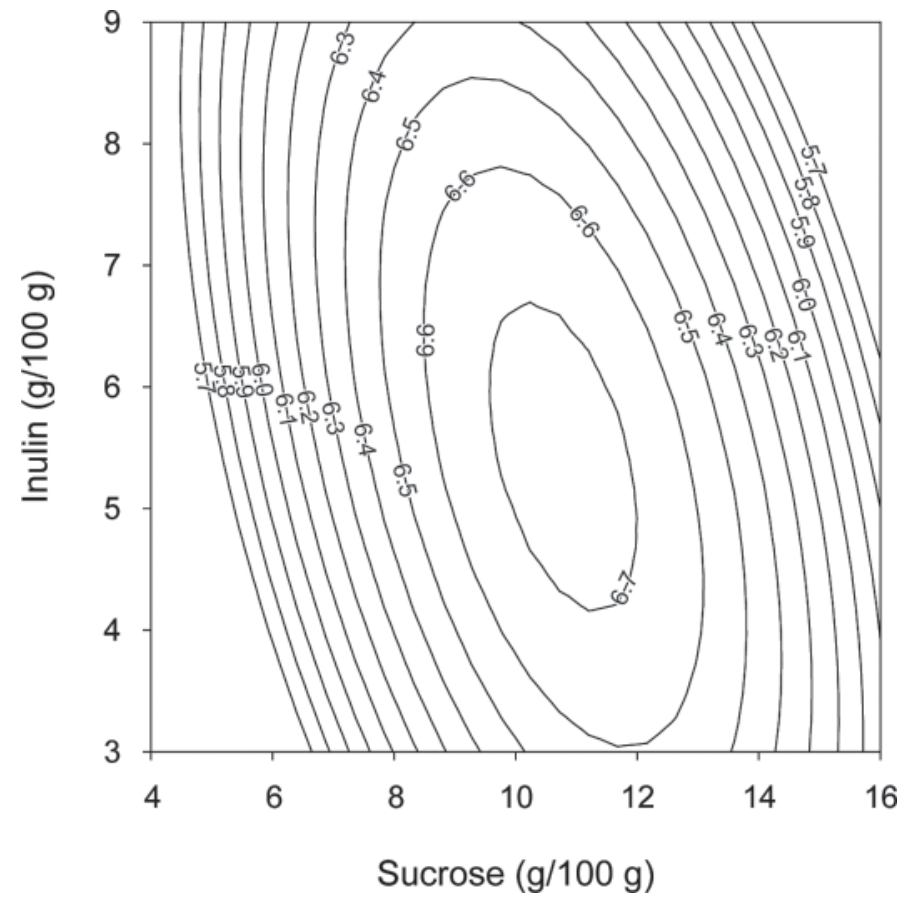

Figure 5. Contour plot of acceptability of prebiotic low-fat dairy dessert as related to sucrose and inulin concentrations (lemon flavor concentration $=75 \mathrm{mg} / \mathrm{kg}$ ).

ferences in the intensity of some attributes and overall acceptability were evaluated (Figure 6 ). The prebiotic low-fat dessert was creamier and thicker than the reference full-fat sample. Taking into account that thickness and creaminess in a low-fat custard are lower than those of a regular fat sample (Tárrega and Costell, 2006), this result indicated that $5.5 \mathrm{~g} / 100 \mathrm{~g}$ of the inulin blend (50:50) increased viscosity and creaminess of low fat dessert enough to exceed those of a full-fat sample. The lemon flavor was perceived as less intense in the full-fat sample although it contained twice the concentration of the low-fat sample. This difference can be due to both the flavor retention effect of fat in the whole milk sample and the effect of inulin as flavor enhancer in the prebiotic sample (Tárrega and Costell, 2006). Regarding sweetness, the prebiotic low-fat dessert contained less sucrose than the reference sample; no difference was found in perceived sweetness between them, which can be attributed to the sweetener effect of short-chain inulin. In spite of the fact that differences in the sensory characteristics were perceived by consumers, they found the low-fat dessert to be as acceptable as the regular fat dessert.

\section{CONCLUSIONS}

In low-fat dairy desserts, the addition of an inulin blend (short- and long-chain) affects acceptability. The effect is dependent not only on the concentration 


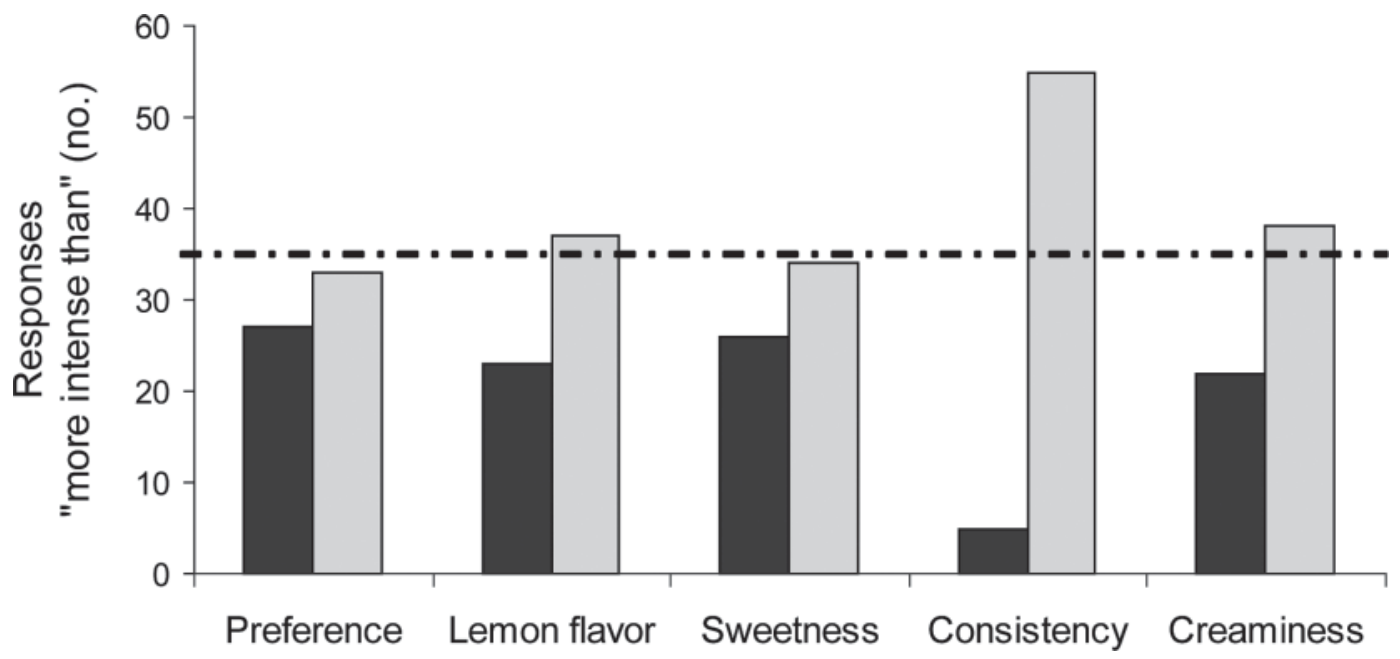

Figure 6. Sensory comparison of the low-fat dairy dessert (gray bars) and the dessert with regular fat content (black bars). The dotted line indicates the minimum value of response for which the difference is significant $(\alpha=0.05)$.

of added inulin but also on the sugar concentration. The relationship between the acceptability of low-fat dairy desserts and composition has been established. The obtained model predicts acceptability in terms of the concentration of sucrose, inulin, and lemon flavor. The prebiotic low-fat dairy dessert selected in the optimization study, besides the reduction in the amount of fat, also contained less sugar (12\% reduction) and less lemon flavor (60\% reduction) than the reference product (regular fat content), without degree of acceptability being affected.

\section{ACKNOWLEDGMENTS}

The financial support of MICIN, Spain (Project AGL 2007-63444 and Tárrega's contract within the Juan de la Cierva Programme) and financial support of LATU (Montevideo, Uruguay) for Arcia's stay at IATA (Valencia, Spain), and the support of Chr. Hansen S.A. (Barcelona, Spain), Lucta S.A. (Barcelona, Spain), Brenntag Química (Barcelona, Spain), and Central Lechera Asturiana (Granda-Siero, Spain) for providing free samples of the ingredients, are all gratefully acknowledged.

\section{REFERENCES}

Abrams, S. A., I. J. Griffin, K. M. Hawthorne, L. Liang, S. K. Gunn, and G. Darlington. 2005. A combination of prebiotic short- and long-chain inulin-type fructans enhances calcium absorption and bone mineralization in young adolescents. Am. J. Clin. Nutr. 82:471-476.

Acosta, O., F. Víquez, and E. Cubero. 2008. Optimisation of low calorie mixed fruit jelly by response surface methodology. Food Qual. Prefer. 19:79-85.

Arcia, P. L., S. Navarro, J. Catalá, E. Costell, and A. Tárrega. 2010. Using seeding technique in the manufacture of inulin enriched dairy desserts. Page 193 in Conf. Proc. Food Innova 2010. Editorial UPV, Valencia, Spain.

Bayarri, S., I. Chuliá, and E. Costell. 2010. Comparing $\lambda$-carrageenan and an inulin blend as fat replacers in carboxymethyl cellulose dairy desserts: Rheological and sensory aspects. Food Hydrocolloids 24:578-587.

Biedrzycka, E., and M. Bielecka. 2004. Prebiotic effectiveness of fructans of different degrees of polymerization. Trends Food Sci. Technol. 15:170-175.

Cardarelli, H. R., F. C. A. Buriti, I. A. Castro, and S. M. I. Saad. 2008. Inulin and oligofructose improve sensory quality and increase the probiotic viable count in potentially synbiotic petit-suisse cheese. Food Sci. Technol. 41:1037-1046.

Coudray, C., J. C. Tressol, E. Gueux, and Y. Rayssiguier. 2003. Effects of inulin-type fructans of different chain length and type of branching on intestinal absorption and balance of calcium and magnesium in rats. Eur. J. Nutr. 42:91-98.

Damasio, M. H., E. Costell, and L. Duran. 1999. Optimising acceptability of low-sugar strawberry gels segmenting consumers by internal preference mapping. J. Sci. Food Agric. 79:626-632.

De Castro, T. M., P. L. M. Cunha, R. D. Barreto, D. M. Amboni, and E. S. Prudencio. 2009. Effect of oligofructose incorporation on the properties of fermented probiotic lactic beverages. Int. J. Dairy Technol. 62:68-74.

Deshpande, R. P., M. S. Chinnan, and K. H. McWatters. 2008. Optimization of a chocolate-flavored, peanut-soy beverage using response surface methodology (RSM) as applied to consumer acceptability data. Lebenson. Wiss. Technol. 41:1485-1492.

Franck, A. 2002. Technological functionality of inulin and oligofructose. Br. J. Nutr. 87:S287-291.

Gacula, M. 1993. Design and Analysis of Sensory Optimization. Food and Nutrition Press, Trumbull, CT.

Gan, H.E., R. Karim, S.K.S. Muhammad, J.A. Bakar, D.M. Hashim, and R. Rahman. 2006. Optimization of the basic formulation of a traditional baked cassava cake using response surface methodology. Lebenson. Wiss. Technol. 40:611-618.

Ghoddusi, H. B., M. A. Grandison, A. S. Grandison, and K. M. Tuohy. 2007. In vitro study on gas generation and prebiotic effects of some carbohydrates and their mixtures. Anaerobe 13:193-199.

Glibowski, P., and S. Pikus. 2011. Amorphous and crystal linulin behaviour in a water environment. Carbohydr. Polym. 83:636-639.

González-Tomás, L., S. Bayarri, and E. Costell. 2009. Inulin-enriched dairy desserts: Physicochemical and sensory aspects. J. Dairy Sci. 92:4188-4199. 
González-Tomás, L., S. Bayarri, A. J. Taylor, and E. Costell. 2007. Flavour release and perception from model dairy custards. Food Res. Int. 40:520-528.

Granato, D., I. A. Castro, L. S. N. Ellendersen, and M. L. Masson. 2010a. Physical stability assessment and sensory optimization of a dairy-free emulsion using response surface methodology. J. Food Sci. 75:S149-155.

Granato, D., J. C. B. Ribeiro, I. A. Castro, and M. L. Masson. 2010b. Sensory evaluation and physicochemical optimisation of soybased desserts using response surface methodology. Food Chem. 121:899-906.

ISO. 2005. International Standard 5495. Sensory analysis. Methodology. Paired comparison test. Ref. No. ISO 5495:2005. International Organization for Standardization, Geneva, Switzerland.

ISO. 2007. International Standard 8589. Sensory analysis. General guidance for the design of test rooms. Ref. No. ISO 8589:2007. International Organization for Standardization, Geneva, Switzerland.

Kip, P., D. Meyer, and R. H. Jellema. 2006. Inulins improve sensoric and textural properties of low-fat yoghurts. Int. Dairy J. 16:1098-1103.

Lobato, L. P., M. V. E. Grossmann, and M. T. Benassi. 2009. Inulin addition in starch-based dairy desserts: Instrumental texture and sensory aspects. Food Sci. Technol. Int. 15:317-323.

MacFie, H. J., N. Bratchell, K. Greenhoff, and L. V. Vallis. 1989. Designs to balance the effect of order of presentation and first-order carry over effects in Hall tests. J. Sens. Stud. 4:129-148.
Modzelewska-Kapituła, M., and L. Kłębukowska. 2009. Investigation of the potential for using inulin HPX as a fat replacer in yoghurt production. Int. J. Dairy Technol. 62:209-214.

Roberfroid, M. B., J. Van Loo, and G. Gibson. 1998. The bifidogenic nature of chicory inulin and its hydrolysis products. J. Nutr. 128:11-19.

Tárrega, A., and E. Costell. 2006. Effect of inulin addition on rheological and sensory properties of fat-free starch-based dairy desserts. Int. Dairy J. 16:1104-1112.

Tárrega, A., A. Rocafull, and E. Costell. 2010. Effect of blends of short and long-chain inulin on the rheological and sensory properties of prebiotic low-fat custards. Lebenson. Wiss. Technol. 43:556-562.

Tarrega, A., C. Yven, E. Sémon, and C. Salles. 2008. Aroma release and chewing activity during eating different model cheeses. Int. Dairy J. 18:849-857.

Tungland, B., and D. Meyer. 2002. Non-digestible oligosaccharides (dietary fibre): Their physiology and role in human health and food. Comp. Rev. Food Sci. Food Saf. 3:73-92.

Villegas, B., A. Tárrega, I. Carbonell, and E. Costell. 2010. Optimising acceptability of new prebiotic low-fat milk beverages. Food Qual. Prefer. 21:234-242.

Weel, K. G. C., A. E. M. Boelrijk, A. C. Alting, P. J. J. M. Van Mil, J. J. Burger, H. Gruppen, A. G. J. Voragen, and G. Smit. 2002 Flavor release and perception of flavored whey protein gels: Perception is determined by texture rather than by release. J. Agric. Food Chem. 50:5149-5155. 